\title{
-3SERVATIONS ON THE PRAWN FISHERY OF THE COCHL. BACKWATERS WITH SPECIAL REFERENCE TO THE STAKE NET CATCHES
}

\author{
M. KRISHNA MENON AND K. RAMAN \\ (Central Marine Fisheries Research Institute)
}

\section{INTRODUCTION}

THE long chain of backwaters extending along the central and southern parts of the Kerala State provides rich prawn fishing grounds, where fishing is carried out practically all the year round. The fishery is not confined to the backwaters only, but extends into the extensive networks of canals connected with them and also to the paddy fields bordering the "Vembanad Kayal' at about the middle of the chain. Though reliable statistics are yet lacking there is little doubt that the annual production may amount to several thousands of tons.

These backwaters stretch for the most part parallel to the coast-line and are separated from the sea in some places only by a narrow belt of sand, not more than a few hundred feet in width. In other places this sandy belt broadens out considerably, and may be a few miles across at the broadest points. There are a number of openings establishing communication with the sea, and facilitating the passage of water to and fro between the two. For about 4 months in the year from June to August the water, at least the upper layers in the deeper regions, is almost fresh (George, 1958) due to the large admixture of freshwater from rain, from land drainage and from the numerous streams opening into them. Later in the year there is a steady rise in salinity and in April to May it is only slightly below that of sea-water. The bottom in most regions is formed of mud containing large amounts of organic detritus.

Penæid prawns which contribute the bulk of the catches are known to breed exclusively in the sea, with the exception of an Australian species, Metapenaus mastersii. The larval development is completed in 2 to 3 weeks and the early post-larvæ or fry ascend into creeks, estuaries and backwaters in large numbers, where conditions for their early life and growth are presumably quite favourable. During the breeding period, which is fairly protracted in the case of some species, vast numbers of such fry pass into these 
backwaters (Menon, 1951; George, 1958) and the rich prawn fishery of these waters consequently owes its existence to this habit of the fry.

The Cochin backwaters, forming the northern extension of the Vembanad Lake (Kayal), abound in these young and growing Penæid prawns during the greater part of the year and the fishery they support is therefore quite rich and lucrative. Various types of nets like Stake nets, Chinese nets, Drag nets, Cast nets, etc., and ingenious devices like 'Pachil' (Panikkar, 1939; Menon, 1951; Gopinath, 1953; Panikkar and Menon, 1955) are made use of in the capture of prawns; but the stake net catches are comparatively more abundant and may account for a substantial part of the total.

It is difficult at present even to make an approximate estimate of the magnitude of the annual catch due to lack of data. Though we have a fairly good knowledge of the different species of prawns inhabiting these waters from the works of Nataraj (1942), Menon (1954) and Gopinath (1955) their fluctuations in abundance from month to month, size range, growth and other aspects of their bionomics are yet to be fully understood. It was therefore thought that a regular quantitative study of the catches of a couple of stake nets carried out for a fairly long period may serve to reduce the deficiency in this regard to a great extent.

\section{Material AND Methods}

Two nets were chosen for making these observations. One was located a little to the north of the entrance to the Cochin harbour near the village of Azhikal and the other about 6 to 7 miles south of it, at Thevara (Fig. 1). Between Thevara and the island of Kumbalam to the south of it there is a narrow gap connecting the backwaters with a network of canals passing eastwards for several miles into the interior. These two nets were chosen with a view to ascertain whether and to what extent the catches might differ in two such situations. Easy accessibility, from the point of view of distance, has also received due consideration in their choice.

Observations relating to the weight of the total catch of each of the two nets and the weight of prawns alone were made on alternate days. A random sample of the prawn catch of each net was collected on one day in a fortnight for analysis and study in the laboratory (Fishing is usually carried out only on 8 to 9 days in a fortnight; sometimes the number of days may be less). The sample was first sorted out into the different species composing it and later the weight, number of individuals, etc., in respect of each were determined. The proportion of each species, by weight as well as by numbers 
was calculated from the above figures. Total lengths (from the tip of the rostrum to the extremity of the telson) of all individuals of each species in the sample were also usually recorded. When the number was appreciably large on any day only a portion was mèasured. No effort was made to measure the sexes separately, since on most days a part of the sample consisted invariably of young prawns that could hardly be sorted as males or females. These measurements were subsequently used for drawing length frequency curves for each species from month to month in order to follow, if possible, their growth rates.

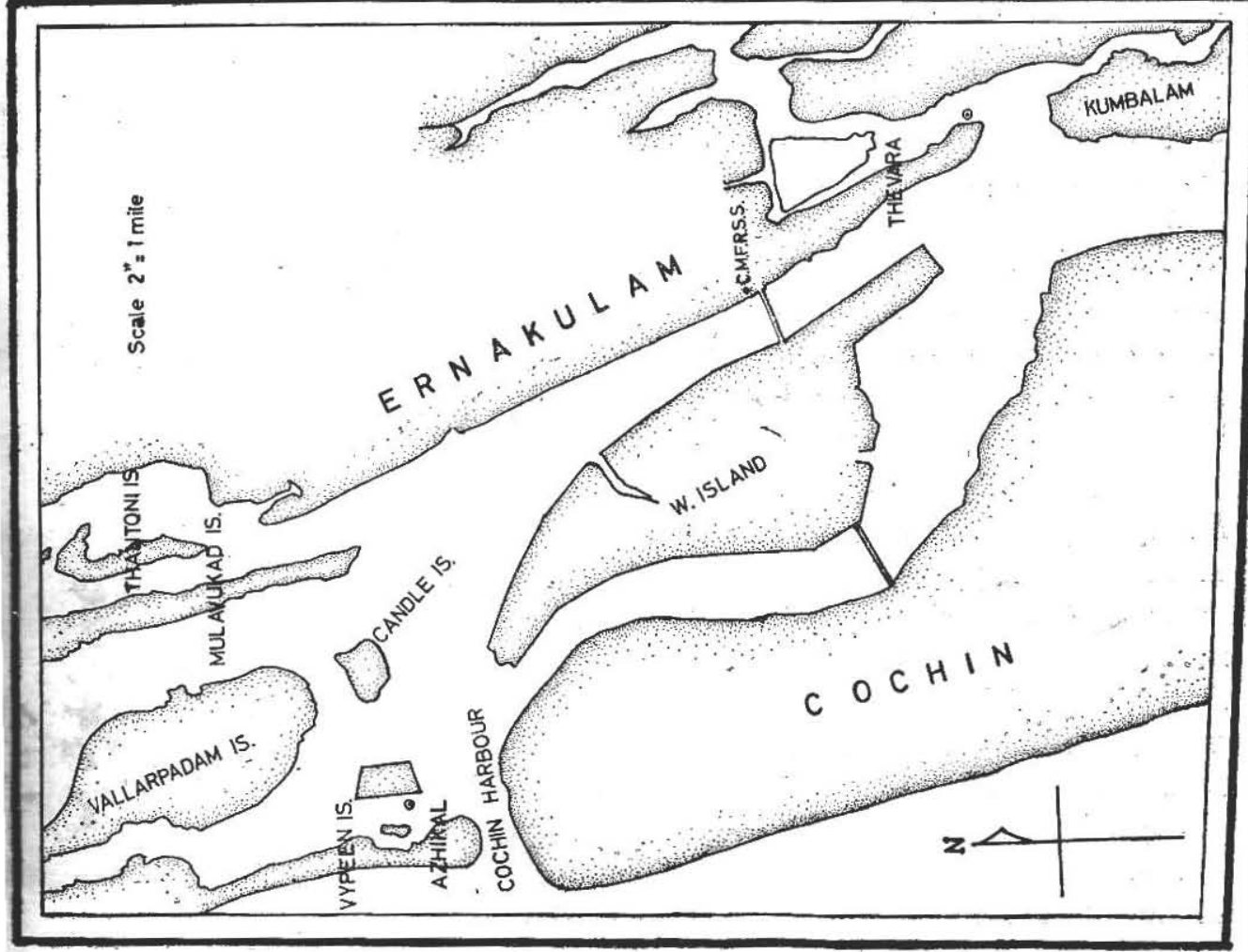

FIG. 1. Showing the location of the two stake nets, at Azhikal and Thevara (indicated by dotted circles).

Description of a Stake Net (Malayalam: Valu vala, Oonni vala).--It is a long tapering net, usually about $50^{\prime}$ or a little less in length. The circumference of the mouth may be about $60^{\prime}$. It is usually made of -cottonyarn; but the part bordering the mouth is of coir yarn. The mesh size varies in different parts; around the mouth it may be as much as $8^{\prime \prime}$ (from 
knot to knot when stretched); immediately behind it is reduced to about $4 \frac{1}{2}$ and still farther back it is progressively $1 \frac{1}{2}$ " and $1^{\prime \prime}$ and at the cod end it is only $\frac{1}{2}^{\prime \prime} .^{*}$ There are 4 coir loops or rings around the mouth for fixing the net to a pair of stakes driven into the bottom mud and the narrow open cod end is tied up with a piece of rope before the net is fixed. When set in position the lower border of the mouth either touches the bottom or remains close to it.

Mode of Operation.-Like the 'Dol' and 'Bokshi' nets of Bombay and similar nets in use elsewhere in the country, the net described above is also operated with the help of tidal action. It is set in position just before or soon after the ebb tide has set in and is usually hauled out when the tide turns. The time of operation is usually in the evenings extending into the early hours of the night or at daybreak. Both during the bright and the dark halves of the month fishing is restricted to about half the period, commencing on the tenth or eleventh day (Dasami or Ekadasi) and ending on the fourth or fifth day after the new and full moon. On other days the tides seem to be apparently not quite favourable for this type of fishing. During the hot months the number of days on which fishing is done is usually less in each half, probably for the same reason.

On some days, when the catches are satisfactory and tides favourable, fishing may be done both in the evening and early morning of the same day. This however happened only on a few days during the course of these observations extending from September 1956 to August 1958. On other days the net is operated only once. Even during the monsoon period of June, July and August fishing continues without interruption, provided high floods causing swift currents do not occur. In 1958, because of unusually favourable conditions prevailing operations were continued without a break for about 70 days, from 15-6-1958 to 23-8-1958 and again for 23 days from 27-8-1958 to $18-9-1958$ in the case of the net at Azhikal. At Thevara also there was uninterrupted fishing for a period of 73 days during the same months. To what extent stake net fishing depends on tidal action will be clear from this. When floods and swift currents prevail it is not safe to set the nets in position since the large quantities of floating debris may get entangled in them and they may get torn. It is only under such conditions that stake net fishing is temporarily suspended in the Cochin backwaters.

* The length, mesh size, etc,, are subject to some variation from net to net. 


\section{OBSERVATIONS}

The data collected can be presented conveniently in two sections. A comparison of the quantities caught by the two nets from month to month, the percentages contributed by the various species and their fluctuations at the two places together with factors influencing the volume of catches, if any, and other relevant observations may form the first section. A brief discussion of some aspects of the biology of these prawns, based on the collected data, may be attempted in the other.

\section{Section I}

Monthly Catches.-It has been stated in an earlier paragraph that observations on the quantities caught were recorded on alternate days. From these the total catch and the prawn catch (varying quantities of small fish are also usually caught) were calculated at the end of each fortnightly period of operation. The estimated monthly totals and the percentage values of prawns in each month at the two places are given in Table $\mathrm{I} . \dagger$

Comparing the prawn catches in successive months at the two places it becomes at once apparent that those at Thevara are consistently lower than at Azhikal. The nearness of the latter place to the harbour entrance and the greater strength of the tidal currents are obviously two of the factors apparently contributing to the better catches there.

Further the quantity of prawns caught and the total catch in the second year (1957-58) at Azhikal dwindled to less than half of that of the previous year. Though the number of fishing days is also less the difference does not seem to be large enough to account adequately for the fall in catches. The monthly estimated figures also, except in July, August and September, as might be expected, differ strikingly. The difference in the July catch of the two years is however not so great and, strangely enough, the figures of August and September, though small, are higher in 1958.

At Thevara also the catch in the second year is definitely less; but the fall is not so steep as at the former place. The number of days also follows the same trend. Likewise the catch in July and the succeeding two months in 1958 is higher, thus repeating practically the trend noted at Azhikal.

The average monthly catch at Azhikal in 1956-57 is about $110 \mathrm{~kg}$. In November and December 1956 and January, April, May and June 1957

† In certain months-September, October, December and February-fishing was done both in the evening and early morning at Azhikal. On a few days however there may have teen only one fishing and the totals for those months may consequently be slight overestimates. This possibility was açcidentally overlooked at the time data were being collected. 
TABLE I

Estimated total catches and prawn catches (in Kg.), percentage of the latter and No. of fishing days in each month from November 1956 to October 1958 at the two places

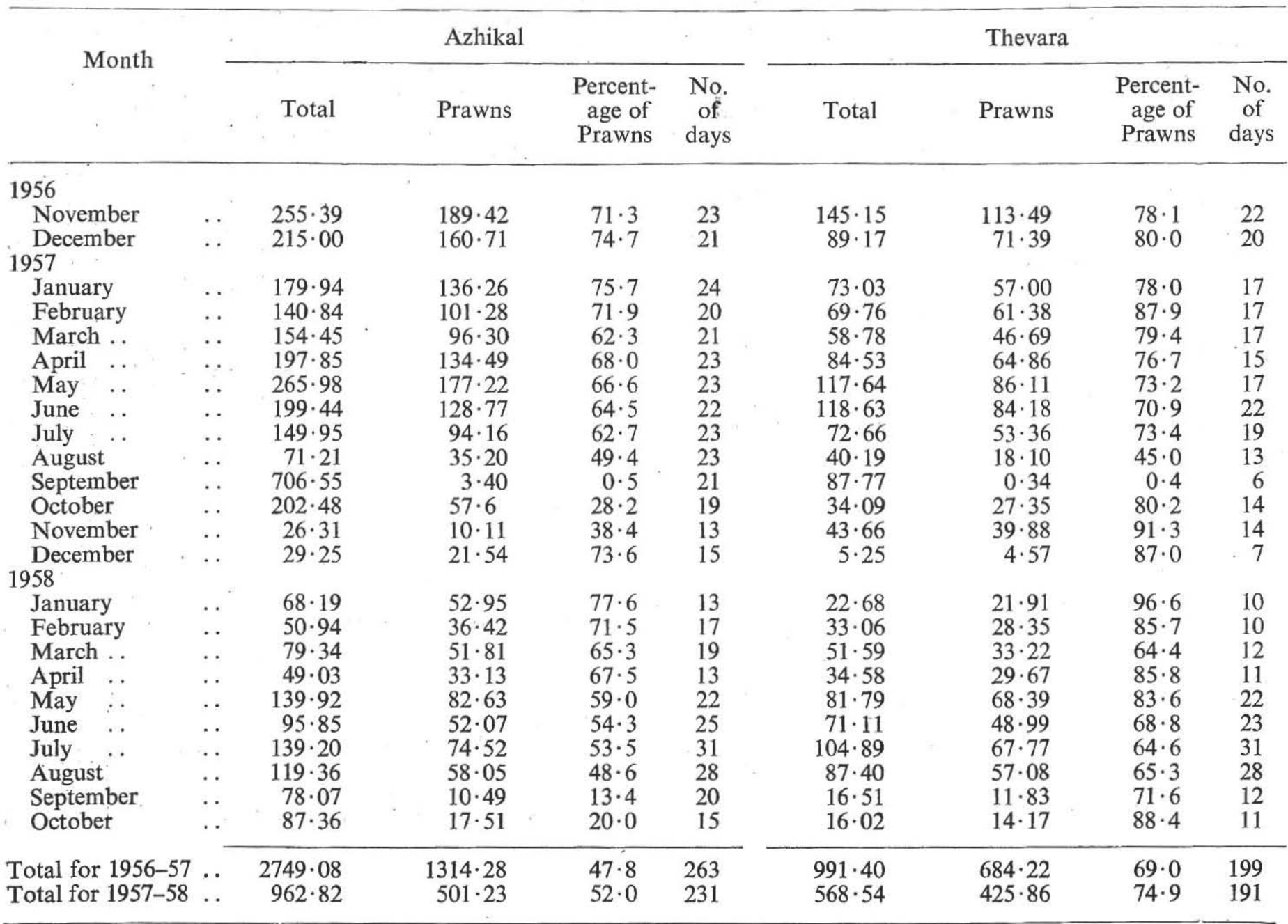


the estimated figures are markedly higher and these six months may therefore be regarded as probably the best months for prawns. In view of the abnormally low catches of the following year it may not be surpising that in some of these months similar good catches have not been obtained. The landings at Thevara also, on the same basis, were good in the first year.

Proportion of Prawns.-The highest percentage of prawns in the total catch at Azhikal was recorded in January 1958 and was 77.6 and the lowest $(0 \cdot 5)$ in September 1957. Comparing the monthly figures in the two years (Fig. 2) it would seem that the fluctuations in general follow the same pattern, though the magnitude in any particular month may show considerable disparity as is seen in November.

At Thevara the highest percentage was 96.6 and was recorded in the same month, viz., January 1958. The lowest likewise (0.4) was in September 1957. Despite this similarity, the pattern of monthly fluctuations in the two years, as illustrated by the curves, is quite different. This is particularly true in respect of 1957-58 and will be clear from a glance at Fig. 2. In 1956-57 the trend is approximately similar to that at Azhikal, except in January, February, April and July. If the low catch figures of the second year could be regarded as indicative of an abnormal year the previous year (1956-57) and the data pertaining to that year should, in all probability, reflect approximately the normal condition of the fishery.

It may also be noted here that in both the years, except in 2 or 3 months, the monthly percentage values of prawns is definitely higher at Thevara. This is true in regard to the annual values also.

Factors influencing Catches.-It has been pointed out earlier that the nearness of Azhikal to the harbour mouth and the stronger tidal flow there might probably account for the better catches of that net. For explaining the fluctuations (daily, monthly, etc.) noted at both places other factors like rainfall and the phases of the moon, that are likely to have an influence, may have to be considered.

Rainfall--Among fishermen and others connected with the prawn fishery the belief is widespread here that rainfall exerts a direct influence on the fishery. This and the recommendation of the Indo-Pacific Fisheries Council (1955) that "it may be necessary to begin collecting data on rainfall and meteorological conditions which may be of significance in determining prawn yields" induced the authors to undertake a comparative study of the catch and rainfall data of the two years. In Fig. 3 the monthly rainfall and catch data are shown separately for the two years. The total rainfall 


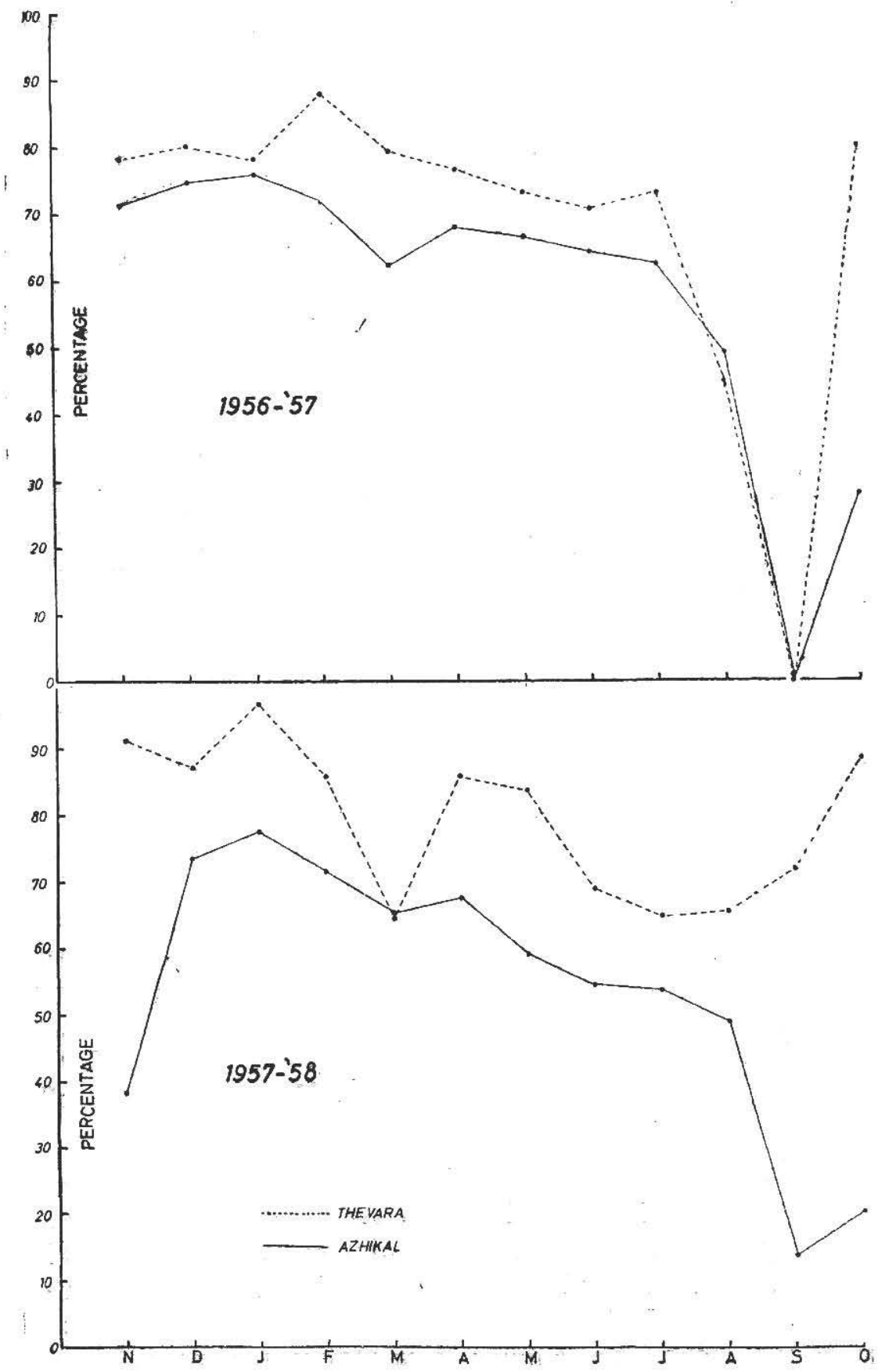

FIG. 2. Percentages by weight of prawns in the total catch at Azhikal and Thevara for the two years $1956-57$ and $1957-58$. 
in 1957 was $3661.7 \mathrm{~mm}$.; in the following year it was much less $(2768.0 \mathrm{~mm}$.). If there is any direct relationship between the two the catches of 1957 should be, on the whole, better than those of 1958 and the catch data presented in Table I have definitely shown that they were so.

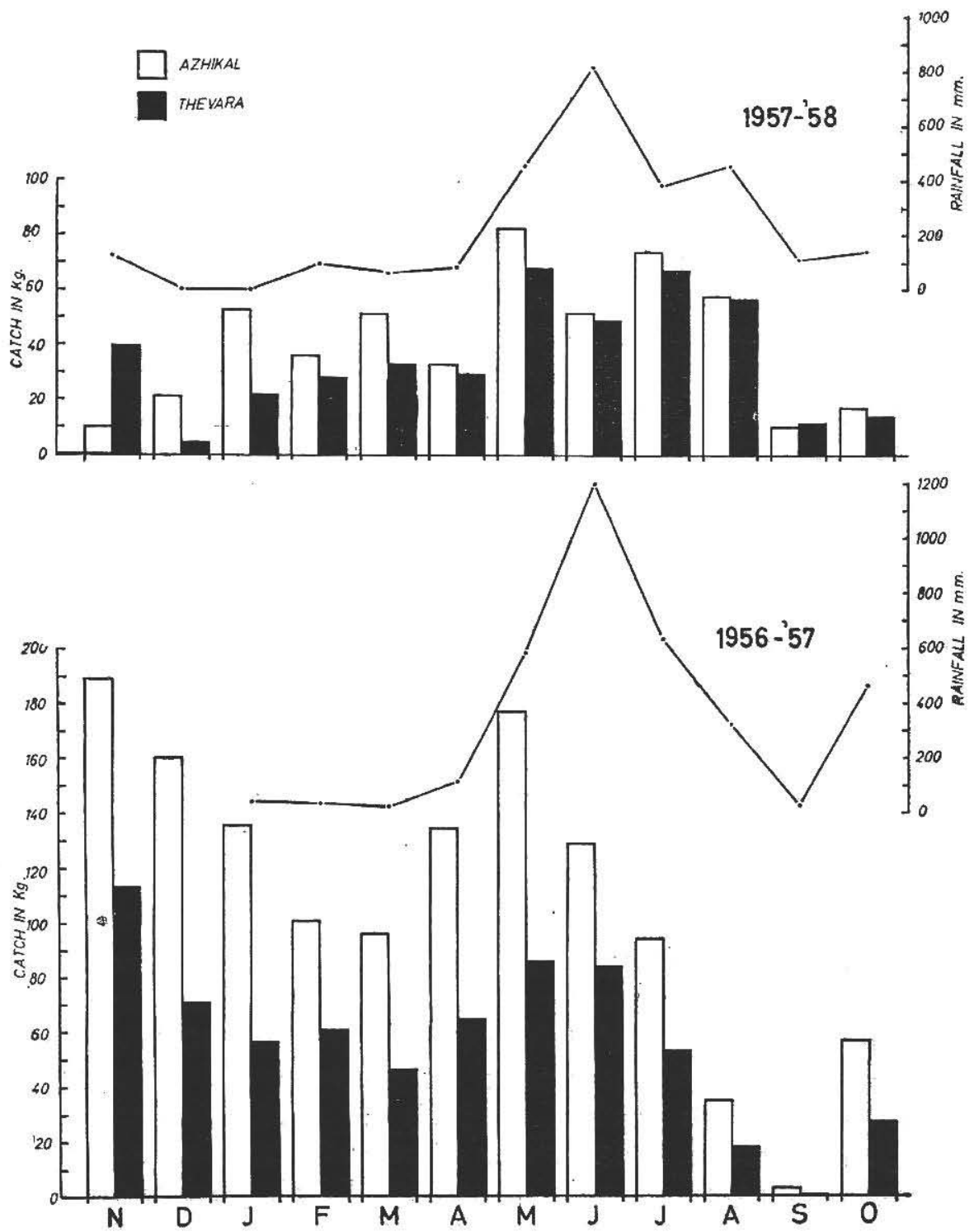

FiG. 3. Monthly prawn catches at the two places in relation to rainfall:

The possibility of the monthly catches also being directly affected by rainfall is indicated by Fig. 3. Since 1957-58 was shown to have been an 
abnormal year for the prawn fishery data relating to 1956-57 may be taken up first for examination. From January to March 1956 the catch at Azhikal declined gradually and the rainfall also shows a reduction from $42 \cdot 0$ to $22.0 \mathrm{~mm}$. The catch at Thevara does not fully agree with that of Azhikal since the figure for February is slightly higher than that of the previous month.

During the three months April to June marking the onset of the southwest monsoon the rainfall was increasingly heavier, reaching the maximum of $1196.2 \mathrm{~mm}$. in June. In the first two months of this quarter the landings at both Azhikal and Thevara have steadily improved, the improvement at Azhikal being more marked. In June however there was an abrupt fall there while at Thevara only a slight reduction is noticeable. From July to September both the rainfall and the catches at the two centres came down progressively. The lowest catches were recorded during September and excepting March the rainfall also was least in that month. In October because of a few showers caused by the north-east monsoon the quantity of rainfall registered an increase and the quantity of prawns caught at both centres rose simultaneously.

Except in the month of June the variations in the prawn catches at both centres are thus seen to have followed fairly closely the pattern of variations in rainfall. It is difficult to trace such an agreement between the monthly catch and rainfall in the next year (1957-58). The maximum catch was in May at the two centres and in the next month there is a fall in the catch in this year also. The lowest catch at Azhikal was in September 1958 and at Thevara in December 1957. Rainfall, on the other hand, was least in January 1958 (only a trace). In November 1957 it was $4.8 \mathrm{~mm}$. and in September 1958 about $111 \mathrm{~mm}$. of rain seems to have fallen. In several other months also differences in rainfall and fluctuations in landings seem to bear little or no relationship.

Phases of the Moon.-Examination of the daily catch figures of each fortnight during the two years has revealed that there is some relationship between them and the phases of the moon. The highest catch was usually recorded on the new or full-moon day or a day or two later, but rarely earlier. It is not clear how this happens. Probably the stronger tidal currents on these days may force a larger volume of water through the nets resulting in the capture of a greater number of prawns. Whether their normal movements are influenced and whether the higher catch is partly due to more active movements is a problem on which no evidence has been collected in the course of these observations. It is likely that both causes may have contributed to the improved catches on these days. 
Species represented and their Proportion in the Catch.-Nataraj (1942) and Menon (1954) have recorded the species composing the prawn fauna of Travancore and the catches from paddy fields respectively. All or most of them should naturally be expected to be caught from the Cochin backwaters irrespective of the gear used. The following is the list of species observed in the stake net catches arranged under their respective families.

Penæidæ

1. Penaus indicus

2. P. carinatuș

3. P. monodon

4. Metapenaus monoceros

5. M. dobsoni

6. M. affinis

7. Parapeneopsis stylifera
Palæmonidæ

1. Palamon rudis

Alpheidæ

1. Alpheus sp.

Among the Penæid prawns listed above three species, viz., P. carinatus, $P$. monodon and $P$. stylifera have occurred quite irregularly and in insignificant numbers and therefore are of no consequence to the fishery. The position of the two non-Penæid species in the list is also much the same. The fishery therefore is supported, practically entirely, by the 4 species of Penæids, viz., $P$. indicus, M. monoceros, $M$.dobsoni and M.affinis. The fluctuations in their proportions from month to month at the two places are illustrated in Figs. 4 and 5. Average monthly percentage values for each species at Azhikal and Thevara were calculated based on weight as well as on numbers separately and are set down in Tables II and III. Percentage values based on weight alone may not be enough to provide a correct idea of the proportion of each species when the majority of individuals of a species show large variations in size, from those of another species. For example, the percentage value of $M$. dobsoni by weight in September 1958 was $50 \cdot 0$ at Azhikal while the value by numbers was 81.9 (Table II). It was so because almost one half of the individuals measured only 50 to $60 \mathrm{~mm}$. In the case of the larger species like $P$. indicus, on the other hand, the percentage value by numbers will usually be considerably smaller than that by weight.

Tables II and III and Figs. 4 and 5 make it quite clear that at both centres $M$. dobsoni is the dominant species during the greater part of the year. At Azhikal the highest percentage value for the species was 86.3 ( 97.8 by Nos.) in the first year (December 1956), and 90.4 ( $91 \cdot 3$ by Nos.) 
in the second year (February 1958). At Thevara the corresponding values were 91.3 ( 98.5 by Nos.) and 79.7 ( 92.0 by Nos.) and were recorded in

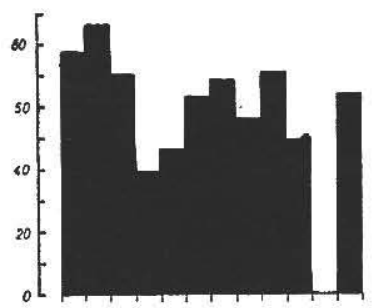

$A Z H I K A L$
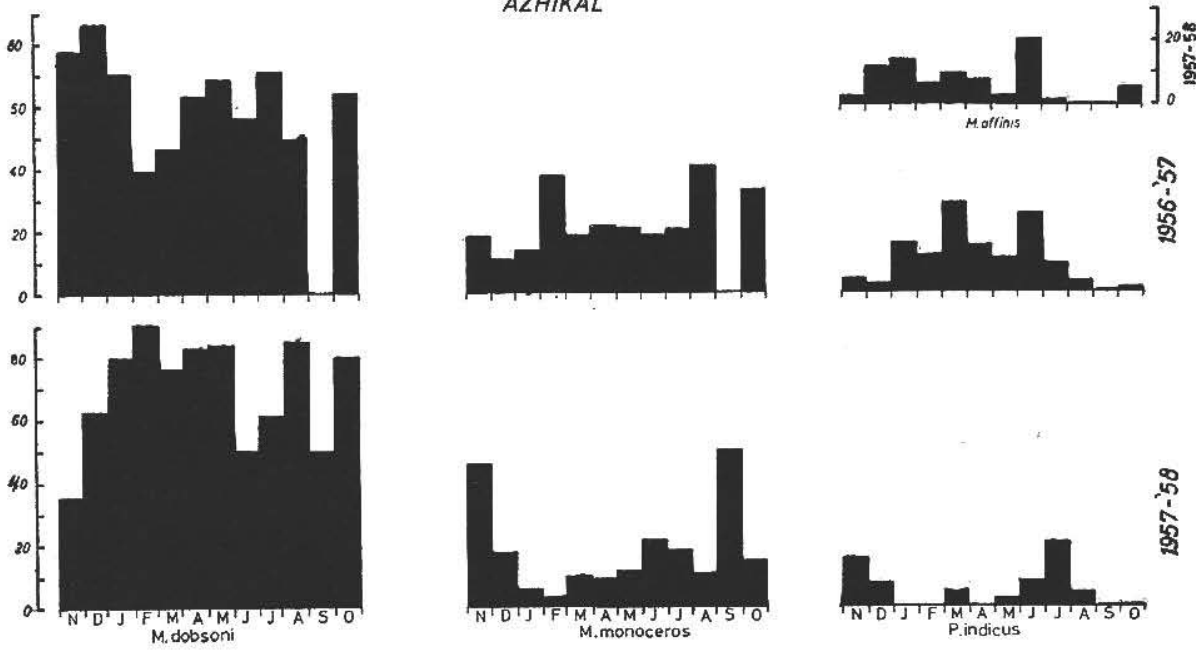

FIG. 4. Monthly variations in percentage by weight of the different species in the total prawn catch at Azhikal.

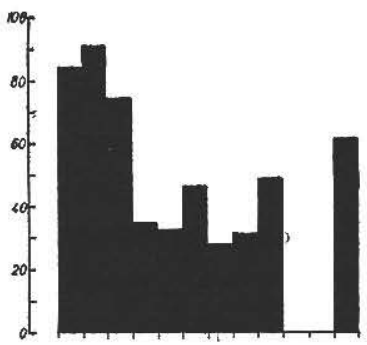

THEVARA
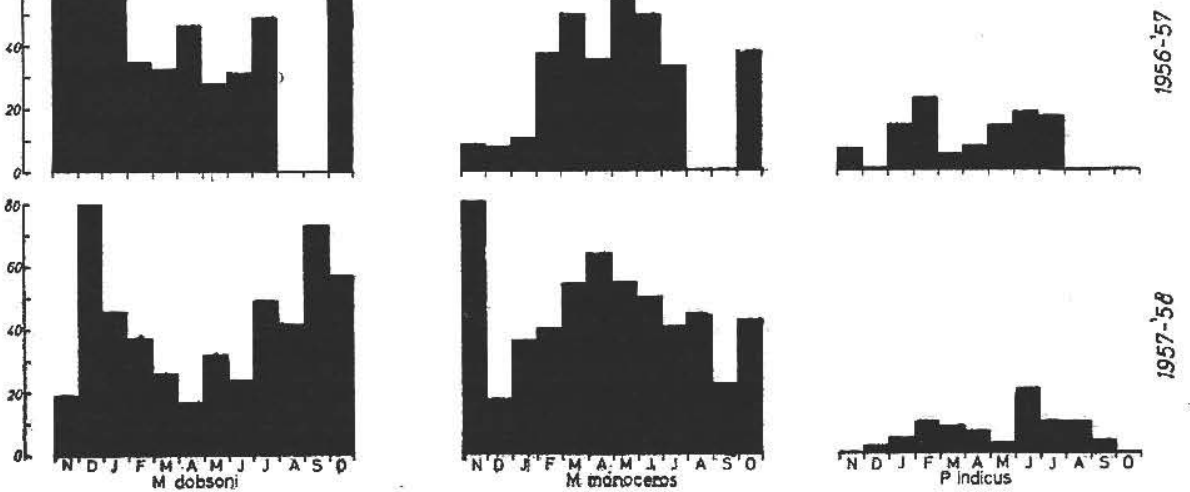

FiG. 5. Monthly variations in percentage by weight of the different species in the total prawn catch at Thevara.

December 1956 and 1957 respectively. The lowest values were 39.5 and 35.6 (59.4 by Nós.) at Azhikal (February 1957 and November 1957) and 
Average monthly percentage values of four species of Penaid prawns in the catches at Azhikal from November 1956 to October 1958

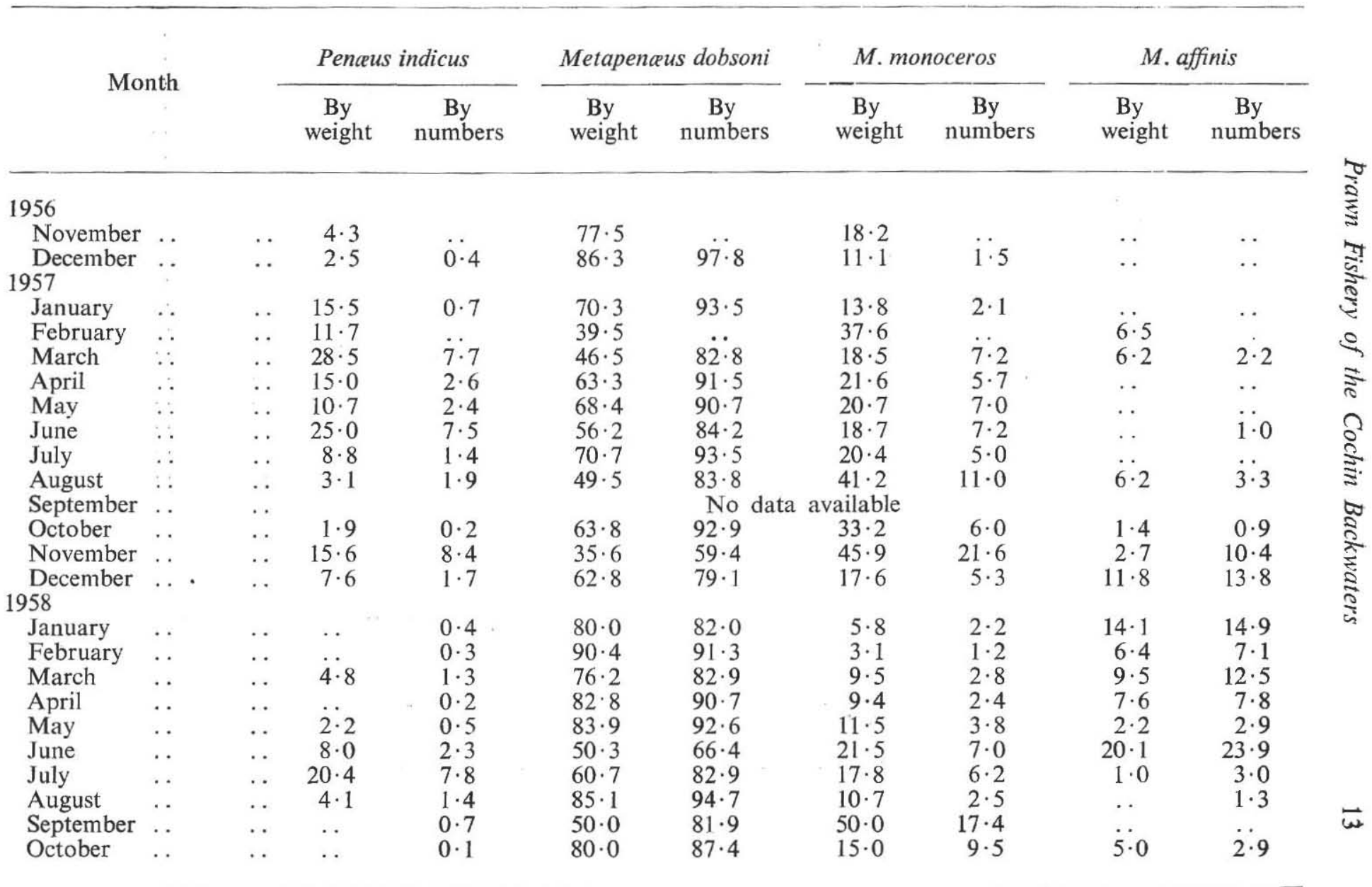




\section{TABLE III}

Average monthly percentage values of four species of Penaid prawns in the catches at Thevara from

November 1956 to October 1958

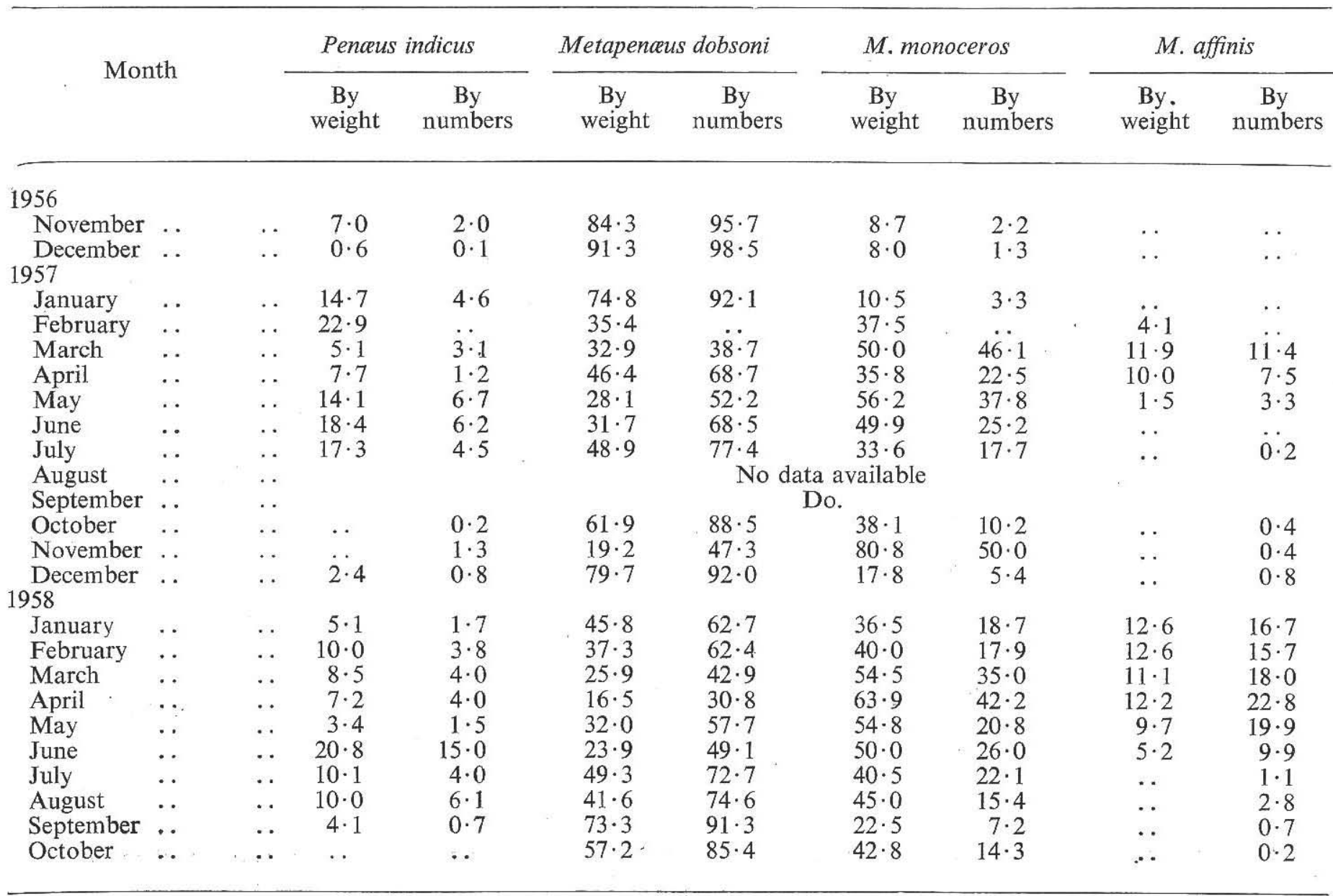


$28 \cdot 1$ ( $52 \cdot 2$ by Nos.) and $16 \cdot 5(30 \cdot 8$ by Nos.) at Thevara (May 1957 and April 1958). It should be noted here that while the highest and lowest values occurred in different months in the two years at Azhikal they were in the same months or in consecutive months at Thevara. Does it imply that the fluctuations in abundance of the constituent species are more regular at the latter centre?

$M$. monoceros seems to occupy the second place in respect of comparative abundance. Its highest percentage values wre $4: 2$ (11.0 by Nos.) and 50.0 (17.4 by Nos.) in the first (August 1957) and second years (September 1958) at Azhikal. The lowest were $11 \cdot 1$ ( 1.5 by Nos.) and $3 \cdot 1$ (1.2 by Nos.) respectively (recorded in December 1956 and February 1958). At Thevara the highest values were 56.2 (37.8 by Nos.) and $80.8(50.0$ by Nos.) and were noted in May 1957 and November 1957. Similarly the lowest were $8.0(1.3$ by Nos.) and $17 \cdot 8(5.4$ by Nos.) both occurring in December of the two years. Apparently there does not seem to be the same regularity in the occurrence of maximum numbers of $M$. monoceros at Thevara as was noted in respect of $M$. dobsoni though the minimum catch has been in the same month (December) in both years. A glance at Table III, however, would show that in March, April and May the values were uniformly good and over 50.0 , going up to 63.9 in April. The apparent irregularity noted above may not therefore be quite so significant as might be assumed.

The third rank from the point of view of abundance is claimed by $P$. indicus. The highest percentage value reached by this species at Azhikal was 28.5 ( 7.7 by Nos.) and $20 \cdot 4$ (7.8 by Nos.) in March 1957 and July 1958 of the two years. The lowest were in September and October in both years. At Thevara the highest values recorded were 22.9 and 20.8 ( 15.0 by Nos.) in February 1957 and June 1958 and the lowest in September and October as at Azhikal. It is remarkable that there is a fair degree of agreement in the occurrence of maximum and minimum numbers of this species at the two centres. It should also be noted here that during the course of routine collection of data on catches of $P$. indicus from these backwaters the somewhat sudden scarcity of this species in the months of September and October has been recorded in some years previously. It is not yet clear how this happens.

M. affinis has occurred only in a few months in the first year at both centres. In the second year though it has been recorded in all months the quantities at Thevara were quite small and negligible in almost half of the year. 
Section II

It was expected that the regular study of fortnightly samples from the catches at the two centres would yield useful information on some aspects of the bionomics of these species, particularly on growth. Monthly length frequencies in respect of each species were therefore worked out and curves drawn, except when the total number of prawns of any species was less than 25 in any month. A similar attempt made a few years back (Menon, 1954) on material obtained from the paddy field prawn fishery was inconclusive and it seemed therefore worthwhile to repeat it on material obtained direct from backwaters during the whole of the year.

Figure 6 shows the curves relating to $M$. dobsoni and M.monoceros for each month of the second year (1957-58). Though the fishery was not so good, data pertaining to that year were chosen because they were available for all the 12 months. A study of these curves is rather disappointing inasmuch as they do not help much in estimating the monthly rate of growth. The modal group from month to month does not show any progressive increase in size. In regard to Azhikal material, for example, the modal group (46-50 mm.) of $M$. dobsoni has remained unchanged for four months, from March to June 1958 and again from August to October '(at 56-60 mm.). This peculiarity is equally evident in respect of material obtained from Thevara, where from February to June 1958 the group has remained consistently steady at $41-45 \mathrm{~mm}$.

It is however possible to draw certain general conclusions about their growth in backwaters. In regard to $M$. dobsoni the modal frequency has varied between $41-45 \mathrm{~mm}$. and $56-60 \mathrm{~mm}$. during the course of the year at Azhikal. Between these extremes the groups measuring $46-50 \mathrm{~mm}$. and 51-55 mm. have dominated each for four months. It would therefore seem that a good portion of the post-larvæ entering these backwaters reach these lengths before they return to the sea or get caught in the commercial fishery. At Thevara also the dominant group has varied in length over the same range, viz., $41-45 \mathrm{~mm}$. to $56-60 \mathrm{~mm}$.; but the period of occurrence of any group among them may not be the same as at Azhikal. The largest individuals obtained at Azhikal belong to the $86-90 \mathrm{~mm}$. group and at Thevara to the $81-85 \mathrm{~mm}$. group. This group and in fact individuals measuring over $\varepsilon 0 \mathrm{~mm}$. occurred in the Azhikal catches only in the months of September, October and November and their proportion never exceeded 2 to 3 per cent. in any month. At Thevara they were even fewer and occurred only in November. Since growth in the species had been dealt with in 
previous papers (1951, 1952 and 1957) little else need be added here on this aspect.
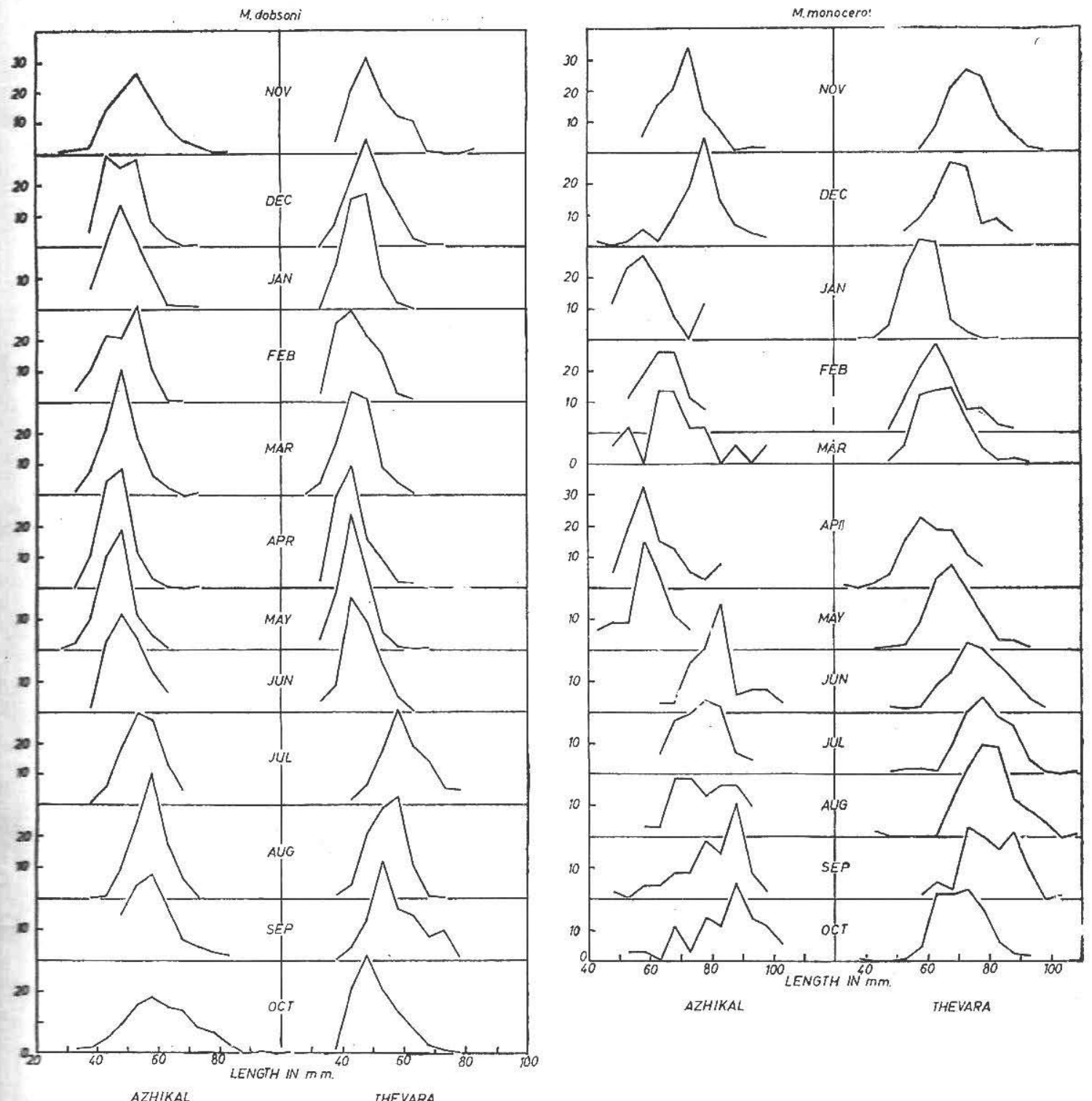

FIG. 6. Length frequercies of the two species in the catches of the two stake nets during November 1957 to Octoter 1958.

M. monoceros.-The modal group in regard to this species has varied in length between $56-60 \mathrm{~mm}$. and $86-90 \mathrm{~mm}$. at Azhikal. The same group has continued to be the dominant group or the next in rank during 
successive months in the case of this species also. For example, the 86$90 \mathrm{~mm}$. group dominated in September and October and in the preceding August they stood second in abundance by a small margin. In regard to the catches at Thevara the curves from May to September seem to provide some indication of the monthly rate of growth. The mode in May was at $68 \mathrm{~mm}$. (66-70 mm. group) and it seems to have moved more or less regularly to $88 \mathrm{~mm}$. ( $86-90 \mathrm{~mm}$. group) in November. The rate of growth among prawns of this species caught in the Thevara net during these months thus seems to be $5 \mathrm{~mm}$. per month. This is in conformity with the observations of George (1960).

The largest group obtained at Azhikal measured 101-105 mm. and was caught only in June and October. They were present in July and the two following months at Thevara. At both centres, however, their proportion is quite small or insignificant. The vast majority of prawns of this species inhabiting these backwaters and connected canals seem to grow only to about $100 \mathrm{~mm}$. or less during their stay in such environments.

Penceus indicus.-Insufficient numbers of prawns in the samples of certain months made it impossible to determine their length frequencies during those months and the series of curves therefore is necessarily incomplete (Fig. 7). It is difficult to draw any conclusions in regard to the rate of growth from their study. The biggest prawns measured come within the group 136 to $140 \mathrm{~mm}$. but it would be clear from a glance at Fig. 7 that the number of individuals measuring over $120 \mathrm{~mm}$. was strikingly few during the six months represented in the figure, even when their total number is reckoned. It would seem that under the conditions prevailing in their brackish-water habitat most of the prawns pass out into the sea or are caught before they are about $100 \mathrm{~mm}$. in length although the adults may reach even double that size.

M. affinis.-The material was not sufficient except in a few months, for length frequency studies.

\section{General Considerations}

Effect of Rainfall.- Some of the observations and data presented in the foregoing pages may be briefly considered here in the light of the results of similar work carried out elsewhere. The influence of rainfall on prawn fisheries have been observed by workers in America and Australia. Hildebrand and Gunter (1953) have noted that during dry years the catches of Penceus setiferus Linn. in Texas were low and during the intervening wet years they were high. They have computed the correlation coefficient of the catch 
in 1937 with the average rainfall for that year and the two preceding years and have shown it to be as high as 0.883 . In New South Wales and Queensland, Racek (1959) noticed that ' heavy rainfalls causing extensive river floods' have the effect in the early stage of inducing all prawn stocks to bury themselves in the mud in estuaries. Later, with the steadily decreasing salinity ' a mass migration of nearly all age groups of various species takes place towards the ocean'. It may be interesting to ascertain if the fluctuations in the catches during the monsoon and immediately after (in the first year) described early could be explained by this peculiar behaviour of prawns.

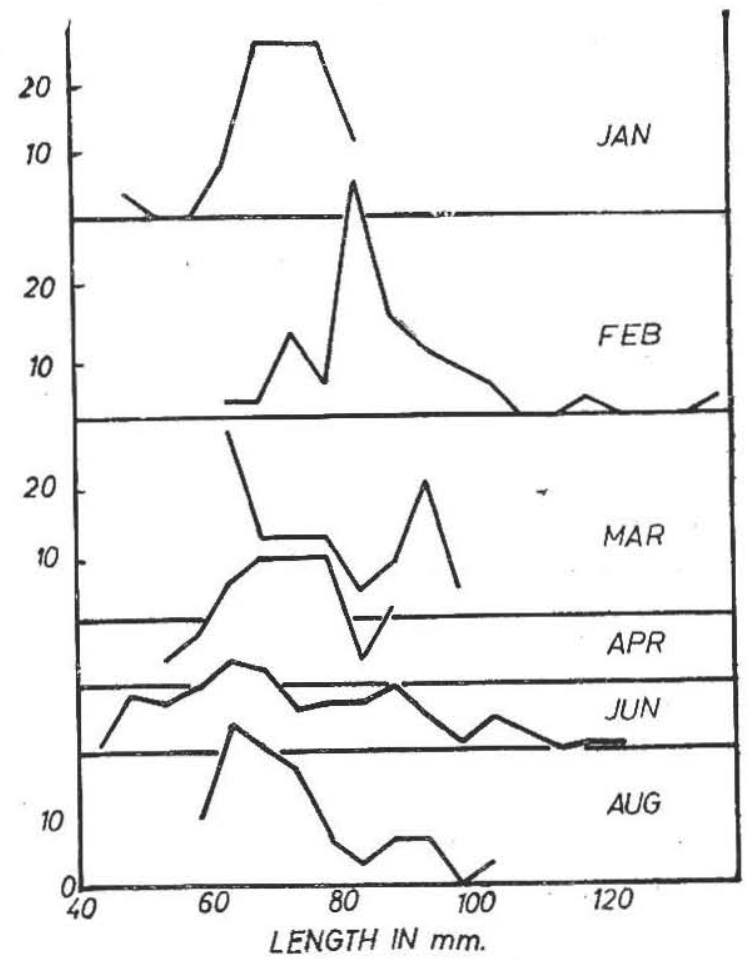

FIG. 7. Length frequencies of $P$. indicus in the Azhikal catches for six months during 1958:

It has been pointed out already that there is evidence for assuming a fairly close connection between rainfall and annual catch. The monthly fluctuations in the catch seem also to be related to the rainfall in the corresponding months in most months in the first year. Such a relationship however is not very much in evidence in the second year. The correlation coefficient of catch with amount of rainfall for the year 1957 has been calculated and the values are 0.54 for Thevara and 0.35 for Azhikal. (The figures, particularly that for Azhikal, are lower than what might be expected from the graph.) 
In respect of monthly catch in the first year that of June is noteworthy since it is much less at Azhikal (slightly less at Thevara) than that of May although the rainfall was more than double the amount. It would seem therefore that the first few showers of the south-west monsoon usually falling in May stimulate an active seaward movement, resulting in a sharp rise in the prawn catch. In subsequent months the catch steadily falls along with decreasing rainfall up to September though the salinity may also be simultaneously declining (George, 1958). In the second year also the same relationship between catch and rainfall exists in May and June. In July of that year, however, though the rainfall is less than half of that of the previous month the catches showed marked improvement. In the next two months they declined somewhat precipitously in September as at Azhikal. The improvement noted in the catch of July may probably be accounted for by the mass migration accompanying decrease in salinity observed by Racek (op. cit.) in Australian estuaries. It did not happen in 1956-57, though for reasons explained elsewhere, that year should be considered to reflect the normal conditions of rainfall and fishery. Presumably factors other than rain and salinity not yet understood may also be exercising some influence on their movements.

Lunar Periodicity.-The highest catch, as stated before, was usually recorded on the new or full-moon day or on either of the next two days. The possibility that this might be caused by the stronger tidal currents prevailing on those days and the more active movements of prawns under lunar influence has also been hinted at. According to Racek (op.cit.) there is pronounced lunar periodicity on the behaviour, abundance, moulting, breeding and offshore spawning runs of Penæid prawns. Wheeler (1937, quoted by Racek) has come to the conclusion that 'the effect of moonlight is one of the most likely factors controlling this periodicity' in respect of abundance and schooling of some decapods including Penæids. Racek, however, is inclined to discount the direct inhibitory effect of moonlight in causing lunar periodicity among predominantly demersal commercial species of Penæid prawns.

Such a sharply defined lunar periodicity, regardless of the factors responsible for it, has been described by him in respect of the seaward migration of two important commercial species of New South Wales, viz., Metapenaus macleayi (Haswell) and Penaus plebijus Hess. This 'spawning run' takes place in ' the earlier part of the outrunning tide chiefly at night' during the summer months December to March. Starting 3 to 5 nights after full-moon the peak of this activity was reached on the 12th night in the case of 
$M$. macleayi and the 16th night in the case of the other species. It stopped on the 19th and 21st day respectively after the full-moon.

Since the stake net catches studied here were obtained in all the 12 months of the year (the quantities showing wide variations) it is not clear if they are always the result of spawning runs similar to those of the Australian species. In the case of non-migratory species like $M$. mastersii (Haswell) periodicity in abundance has been observed, larger schools occurring near the new-moon days. Migratory species also are reported to behave in this way, the behaviour being quite pronounced in estuaries. Since the species dealt with here are migratory, changes in abundance produced in the same way might partly account for the catches.

Lunar periodicity, as observed in the Australian species, occurred usually in the darker half of the month, the peak having been noticed shortly before or after the new-moon. Little difference has been noticed in the quantities caught by stake nets during the brighter and darker fortnights from the Cochin backwaters and it would seem therefore that the factors responsible for the movements of prawns are in operation during both. Could Lunar periodicity account for their abundance and movements in the brighter half of the month? Until planned observations are carried out here no definite opinion can be ventured in answer to this question. Variations in the strength of the tidal flow therefore seem to be the only probable factor, the influence of which is clearly seen on the stake net prawn catches.

In the course of some experiments with three species of prawns Racek (op. cit.) has reported that each species was found to be active, i.e., swimming or crawling, at about the same part of the day and the different species varied considerably in regard to the time and duration of this activity. This behaviour is said to be quite independent of light. It may be rash to base any inference on this, since prawns living in their natural environments may show an altogether different pattern of behaviour. But the author is inclined to assume that light is not a factor causing periodicity and the catch data presented in this paper seem to be in agreement with this view.

Growth.-The attempt to estimate monthly growth by the method of length frequency analysis has not proved quite satisfactory since it has failed to give any definite results. It is true that the curves (Fig. 6) from May to September relating to material from Thevara seem to indicate a monthly rate of $5 \mathrm{~mm}$. for $M$. monoceros. The curves for the rest of the months and those relating to material from Azhikal do not, however, give any support to this conclusion. Some of them are peculiar since the modes 
remain unchanged during a number of months in succession. It has already been stated that vast numbers of post-larvæ enter the backwaters during a fairly long period extending over several months. They seem to grow rapidly and take the place of the modal groups as fast as the latter are removed by fishing. This might also account for the abrupt fall in the length of the modal group in some months.

In the case of M.dobsoni (Menon, 1951 and 1955) and Parapeneopsis stylifera (Menon, 1953) it was possible to deduce the annual growth and the probable duration of life by this method. Kubo (1956) has summarised the results of similar studies on a number of Japanese species of Penæid and Palæmonid prawns. In respect of $M$. monoceros it appears that a carapace length of 27 to $34 \mathrm{~mm}$. (female) and 21.5 to $25.5 \mathrm{~mm}$. (male) is reached by the end of the first year. Since the total lengths corresponding to these carapace lengths are not given in the summary it is not possible to compare them with the maximum length recorded in the stake net catches, which might also, in all probability, be the result of an year's growth.

\section{SUMMARY}

1. Observations made on the catches of two stake nets from the Cochin backwaters, one located at Azhikal close to the entrace to the Cochin Harbour and the other six to seven miles south of it at Thevara during the period November 1956 to October 1958 are discussed in the paper.

2. The total catch, prawn catch and its percentage have been determined for each month during the period of observation.

3. The fluctuations in the prawn catch have been studied and their correlation with rainfall, strength of tidal flow and other factors discussed.

4. The species of prawns composing the catches, as revealed by regular analysis of fortnightly samples from both centres, have been listed, and the quantitative variations from month to month exhibited by the four important Penæids, viz., $P$. indicus, $M$. dobsoni, $M$. monoceros and $M$. affinis have been described.

5. Monthly length frequencies have been worked out and curves drawn in respect of the first three species in order to estimate their monthly rates of growth, if possible. But no definite results were obtained.

\section{ACKNOWLEDGMENT}

Shri P. Karunakaran Nair, Field Investigator and Shri K. Rajasekaran Nair, Laboratory Attender, have rendered valuable assistance in the collection of catch data and samples from Azhikal and in carrying out the 
preliminary analysis and measurements and the authors would like to thank them for it.

\section{REFERENCES}

George, M. J. 1958

1960

Gopinath, K. 1953

1955

Hildebrand, H. H. and

Gunter. 1953

Kubo, I. $1956^{\circ}$

Menon; M; K. 1951

1953

1954

1955

1957

Nataraj, S. 1942

Panikkar, N. K. 1939

and Menon, M. K. 1955

Racek, 1959
.. Observations on the plankton of the Cochin backwaters, Indian J. Fish., 5 (2), 375-401.

.. Notes on the bionomics of the prawn Metapenaus monoceros Fabricius. Indian J. Fish. 6(2), 268-79.

.. Some interesting methods of fishing in the backwaters of Travancore, J. Bombay Nat. Hist. Soc., 51, 466-71.

.. Prawn culture in the rice fields of Travancore-Cochin, India. Proc. I.P.F.C., 6 (2 and 3), 419-24.

Correlation of rainfall with the Texas catch of white shrimp Penous setiferus (Linnaeus). Trans. Amer. Fish. Soc., 82, 151-55.

.. A review of the biology and systematics of shrimps and prawns of Japan. Proc, Indo.-Pac. Fish. Coun., 6 (II and III).

.. The life-history and bionomics of an Indian prawn Merapenceus dobsoni Miers. Ibid., Section II, 80-83.

$\therefore$ Notes on the bionomics and fishery of the prawn Parapeneopsis stylifera (M. Edw.) on the Malabar Coast. $J$. Zool. Soc. India, 5(1), 153-62.

.. On the paddy field prawn fishery of Travancore-Cochin and an experiment in prawn culture. Froc. Indo-Pac: Fish. Coun. 5 (II-III).

.. Notes on the bionomics and fishery of the prawn Metapenaus dobsoni Miers on the south-west coast of India. Indian J. Fish, 2 (1), 41-56.

.. Contributions to the biology of Peræid prauns of the southwest coast of India. I. Sex ratio and movements. lbid., 4 (1), 62-74.

.. A note on the prawn fauna of Travancore. Curr. Sci., 2, 12.

.. The prawn industry of the Malabar coast. J. Bombay Nat. Hist. Soc., 51, 466-71.

Prawn Fisheries of India. Proc. Indo-Pac. Fish. Coun. Symposium on Prawn Fisheries. Sec. II and III, 328-46.

.. Prawn investigations in Eastern Australia. Res. Bull. No. 6, State Fisheries, Chief Secretary's Department, N.S.W. 